Running head: SOCIAL CLASS, IDENTITY UNCERTAINTY AND LIFE SATISFACTION

Subjective Social Class and Life Satisfaction: The Role of Class Consistency and Identity Uncertainty

Bek Wuay Tang

Jacinth J. X. Tan

Singapore Management University

In Press at Asian Journal of Social Psychology

DOI: $10.1111 /$ ajsp.12488 


\begin{abstract}
Drawing on a recent perspective that inconsistent class identities can negatively impact psychological outcomes, the current research explored if the relative benefit of higher subjective social class for life satisfaction would differ depending on whether it is consistent with one's objective social class. In Study 1, across two independent samples from Singapore $(N=1045)$ and the US $(N=492)$, higher subjective social class predicted higher life satisfaction more strongly among those high in objective social class, but less strongly among those low in objective social class. In Study 2, these patterns were replicated in another large US sample $(N=1030)$, and appeared to be driven by lower status-based identity uncertainty (SBIU) linked to higher subjective social class perceptions among high objective social class participants. The role of class-identity perceptions in explaining social class disparities in subjective well-being is discussed.
\end{abstract}

Keywords: life satisfaction, identity uncertainty, social class, subjective well-being 
Subjective Social Class and Life Satisfaction: The Role of Class Consistency and Identity Uncertainty

Socioeconomic inequalities in subjective well-being (SWB) are well-establishedhigher wealth and incomes, both objective and subjective, were associated with higher SWB (Boyce et al., 2010; Diener et al., 1995; Luttmer, 2005; Tan, Kraus, Carpenter, \& Adler, 2020). However, the strength of these associations varied considerably by broader contextual factors, such as a country's economic development (Howell \& Howell, 2008), level of income inequality in society (Cheung \& Lucas, 2015), as well as population density and social mobility (Tan, Kraus, Carpenter \& Adler, 2020). Beyond these contextual factors, it is equally important to understand the role of individual psychological factors in shaping the link between social class and SWB. On this front, studies have found that having a high personal sense of control (B. Chen et al., 2020) and being in highly committed close relationships (Tan, Kraus, Impett \& Keltner, 2020) reduced social class differences in SWB.

Extending the literature on individual psychological factors that shape the social class and SWB link, a recent perspective has posited that experiencing uncertainty about one's current social class identity, termed status-based identity uncertainty (SBIU), can negatively impact one's SWB (Destin et al., 2017). In this research, we examined whether the link between subjective perceptions of social class and SWB assessed as life satisfaction might differ by whether class perceptions are consistent with one's objective social class, and if this could be explained by SBIU.

\section{Social Class and SWB}

Social class has been traditionally defined and assessed in two ways. The first defines social class objectively, as the actual level of material resources that are available to individuals, typically measured by reports of income, educational attainment, occupational status, or a combination of any of these reports (Oakes \& Rossi, 2003; Stephens et al., 2007). 
The second way defines social class subjectively, as the perceived relative rank of individuals in society (Adler et al, 2000; Kraus et al., 2013), typically by asking individuals to judge where they stand in social rank compared to others (Adler et al., 2000). Both measures of social class tended to be moderately correlated with each another at about $r=.32$ (Tan, Kraus, Carpenter \& Adler, 2020), suggesting that they represent distinct dimensions of social class (Cundiff \& Matthews, 2017; Kraus et al., 2012; Tan, Kraus, Carpenter \& Adler, 2020).

The positive association between measures of socioeconomic status and SWB are robust - higher wealth and incomes, both objective and subjective, are associated with higher SWB, at both the population and individual levels (Boyce et al., 2010; Diener et al., 1995; Luttmer, 2005; Tan, Kraus, Carpenter \& Adler, 2020). According to a recent meta-analysis on 357 studies across 103 countries, the association between subjective social class and SWB was .22, while the association between objective social class and SWB was .16 (Tan, Kraus, Carpenter \& Adler, 2020). While the associations between social class and SWB were small, they were moderated by several factors, including country-level wealth (Diener et al., 2003; Tan, Kraus, Carpenter \& Adler, 2020), population density, income inequality and relative social mobility (Tan, Kraus, Carpenter \& Adler, 2020).

In understanding how social class influence SWB, some studies have identified power (i.e. having control of valued resources) and status (i.e. admiration, prestige and respect from others) as mediating mechanisms to the association between social class and SWB (Anderson et al., 2012; Stansfeld et al., 1997; Yu \& Blader, 2020). Relatedly, research also found that higher social class was predictive of greater life satisfaction only amongst Chinese adolescents who felt a low sense of control (B. Chen et al., 2020). In contrast, when these adolescents had a high sense of control, social class did not predict life satisfaction. Furthermore, the interaction effect of subjective social class and sense of control was mediated by self-esteem. Together, the findings from their study suggested that the influence 
of social class was only prominent when basic psychological needs were not met, and pointed to both sense of control and self-esteem as key processes that underlaid the association between social class and well-being (B. Chen et al., 2020).

\section{Social Class-Consistency and SWB}

Most research on social class and SWB have focused on the conceptual overlap between objective and subjective social class, which is the objective knowledge of one's resource levels (e.g. Tan, Kraus, Carpenter \& Adler, 2020). However, the typical moderate association observed between objective and subjective assessments of social class highlighted earlier suggests that their reports may not be consistent with each other. In other words, being objectively high in income or educational attainment may not be consistently perceived as being high in subjective social class. Therefore, as a novel extension of the social class and SWB literature, the current research is focused on how SWB relates to objective and subjective social class as distinct constructs - the former that draws solely on objective knowledge and the latter that draws on evaluative perceptions of resources — both of which can either be aligned or misaligned to each other.

A few reasons have been proposed for why objective and subjective social class might be misaligned with each other (e.g., Tan, Kraus, Carpenter \& Adler, 2020). First, depending on what is considered to be most important or meaningful in one's social or cultural context, subjective social class perceptions may not be equally derived from all of the objective indicators (Adler \& Stewart, 2007). For instance, in some contexts, educational attainment may be the most important indicator of one's subjective status, but in other contexts, it may be income or occupational status. Second, even at a given level of objective status, such as college education, individuals may make finer subjective class distinctions between elite and non-elite colleges (Adler \& Stewart, 2007). As such, a person with a college degree, which is objectively high in social class, might still perceive low subjective social class if he or is from 
a non-elite college. As well, in making subjective judgments of one's social class, people may take into account other important indicators of social class, such as how they compare to their past social class, to surrounding others, or social norms (Tan, Kraus, Carpenter \& Adler, 2020).

Drawing on the distinctions outlined above, we reasoned that although objective and subjective measures of social class share independent and robust positive associations with SWB, their joint association with SWB may vary depending on whether both types of social class measures are assessed as similarly high, similarly low, or mixed. The degree to which both types of social class are assessed as similar or mixed in levels reflect the level of classconsistency. We theorize that individuals who report relatively high (or low) objective social class, but perceive relatively low (or high) subjective social class respectively would experience low class-consistency. On the other hand, individuals who assess their objective and subjective social class to be similarly high or similarly low would experience high classconsistency.

Based on this conceptualization, we hypothesized that among high objective social class individuals, perceiving higher subjective social class is class-consistent and should be strongly linked to greater SWB, compared to perceiving lower subjective social class, which is less class-consistent. However, among low objective social class individuals, we hypothesized that the relative benefit of perceiving higher subjective social class for SWB would still be observed but more weakly, as the perception is less class-consistent ${ }^{1}$.

\section{Status-Based Identity Uncertainty and SWB}

Beyond resources and rank, a recent perspective has proposed that an individual's subjective social class can also be examined as a broader form of status-based identity shaped by the subjective meaning and value that one makes of or attaches to their social class (Destin et al., 2017). According to this theory, one's status-based identity can be derived from three 
sources of subjective meaning, namely narrative, social, and future identities (Destin \& Debrosse, 2017; Destin et al., 2017). Narrative identity refers to the stories that individuals tell to connect their past and present circumstances in a meaningful and coherent manner; social identity refers to one's affiliation and membership in personally valued groups that are associated to social class (e.g. friends, colleagues); and future identity refers to the future self that people envisioned themselves to be and the ways to achieve that outcome, which is often dependent on one's socioeconomic background.

A critical aspect of status-based identity is that individuals' perception of their social class is fluid and can change with the context. For instance, changes in subjective social class could occur as a result of major life changes such as graduation, marriage, divorce or retirement, experiencing social mobility or engaging in upward social comparisons (Destin et al., 2017). Importantly, these changes can elicit a sense of status-based identity uncertainty (SBIU), in which individuals experience feelings of discontinuity in terms of their experiences and expectations of their social class (Destin et al., 2017). For example, college graduates from working-class backgrounds may continue to perceive their social class to be lower than their peers who came from middle-class backgrounds, even though objectively, both groups have the same educational attainment. As well, dating a wealthier partner may also trigger perceptions of higher social class even though objective social class indicators of the individual may remain unchanged.

SBIU elicited by such experiences of inconsistencies in one's social status can negatively influence one's psychological outcomes (Destin \& Debrosse, 2017; Destin et al., 2017). For example, upward social mobility has been argued to increase SBIU among lowerclass individuals by eliciting a sense of cultural mismatch between their original identity shaped by their lower-class backgrounds and their newly elevated social class identity (Destin \& Debrosse, 2017). Consistently with this hypothesis, greater SBIU amongst first 
year college students was linked to lower family income (Destin et al., 2017). Furthermore, greater SBIU was also associated with lower sense of belongingness towards college, lower self-esteem and poorer life satisfaction (Destin et al., 2017), all of which could negatively impact individuals' eventual life outcomes and well-being.

A construct closely related to SBIU is self-concept clarity, defined as the certainty, internal consistency and stability of one's self-concept (Campbell, 1990; Campbell et al., 1996). While SBIU is specifically related to individuals' views about their social class, selfconcept clarity is related to the broader sense of self (Destin et al., 2017). Similar to the findings on SBIU, a large body of work has shown that self-concept clarity predicted outcomes important for maintaining or enhancing well-being. For instance, greater selfconcept clarity was associated with better psychological and relationship outcomes, such as higher positive affect regarding the self (Baumgardner, 1990), higher levels of self-esteem (Campbell et al., 1996; Nezlek \& Plesko, 2001), less rumination (Campbell et al., 1996), greater life satisfaction (Ritchie et al., 2011) and having higher relationship satisfaction and commitment (Lewandowski Jr. et al., 2010).

As higher social class provides the resources and sociocultural contexts that encourage individuals to express themselves freely and to exert control over situations (Kraus et al., 2012; Stephens et al., 2014), recent research has found that self-concept clarity tended to be higher for high objective social class individuals as compared to low objective social class individuals (Boucher, 2020; Na et al., 2018). Furthermore, the studies also suggested that having self-concept clarity could be more important for well-being in upper-class contexts, as the positive association between self-concept clarity and well-being was stronger amongst high objective social class individuals as compared to low objective social class individuals (Boucher, 2020; Na et al., 2018). 
Based on the above review on how SBIU and self-concept clarity may affect SWB, we further reasoned that the relative benefit of higher subjective perceptions of social class on SWB being stronger among high rather than low objective social class individuals, as hypothesized initially, may be explained by SBIU. Specifically, we hypothesized that among high objective social class individuals, perceiving higher subjective social class is more classconsistent and elicits less SBIU, compared to lower subjective social class. This lower SBIU should in turn predict greater SWB among high objective social class individuals.

Conversely, among low objective social class individuals, perceiving higher subjective social class, as compared to lower subjective social class, is less class-consistent and should elicit greater SBIU. Since evidence suggests that self-concept clarity may be more important for the well-being of higher objective social class individuals than lower objective social class individuals (Boucher, 2020; Na et al., 2018), greater SBIU may show only weak or no association with lower SWB among low objective social class individuals.

\section{The Current Research}

To summarise, the current research sought to examine two key hypotheses regarding the association between objective social class, subjective social class, and SWB assessed as life satisfaction. Our primary hypothesis was that among high objective class participants, the relative benefit of perceiving higher, rather than lower, subjective social class for life satisfaction will be stronger than among low objective social class participants. Our secondary hypothesis was that the difference in this relative benefit of higher than lower subjective social class on life satisfaction would be explained by SBIU. Specifically, among high objective social class participants, higher subjective social class elicits lower SBIU, which subsequently predicts greater life satisfaction. However, among low objective social class participants, higher subjective social class elicits higher SBIU, which may subsequently predict life satisfaction weakly or not at all. We tested these hypotheses in two correlational 
studies. Study 1 tested our primary hypothesis in two independent and large datasets collected from Singapore and the United States (US). In Study 2, we sought to replicate the findings using similar measures as in Study 1. In addition, we also included a measure of SBIU to test our secondary hypothesis about the mediating role of SBIU.

\section{Study 1}

In this first study, the basic associations between subjective social class, objective social class, and life satisfaction were examined in two independent online samples of participants from Singapore and US.

\section{Method}

\section{Participants}

Singapore sample. One thousand and fifty-six Singaporean participants were recruited via the Qualtrics online panel, which aimed to provide nationally representative sample. Data from 11 participants were removed due to missing data. The resulting sample size was $1045(50 \%$ females $)$. The mean age for the sample was $34.93(S D=11.21)$. The median monthly household income was 6001 to 8000 in Singapore dollars, and 51\% had at least a college degree. In terms of ethnicity, $82 \%$ were Chinese, $12 \%$ were Malays, $4 \%$ were Indians, and 3\% identified as "Other" ethnicities ${ }^{2}$. The study was conducted in accordance with general ethical guidelines in psychology, approved by the Singapore Management University Institutional Review Board (IRB).

US sample. Six hundred participants from the US were recruited from Amazon Mechanical Turk. After removing 108 participants due to duplicate entries, missing data, and failing attention checks ${ }^{3}$, the remaining sample included 492 participants (56\% females). The mean age for the sample was $35.1(S D=12.0)$. The median annual household income was $\$ 50,001-\$ 75,000$ in US dollars, and 55\% had at least a college degree. In terms of ethnicity, 8\% were African American, 7\% were Asian American, 75\% were European American, 5\% 
were Latino/Latina, $2 \%$ were Native American, and 4\% identified as "Other" ethnicities". The study was conducted in accordance with general ethical guidelines in psychology, approved by the University of Illinois, Urbana-Champaign IRB.

\section{Procedure}

Data from both samples were collected as part of a larger correlational survey. The survey on the Singapore sample was on general perceptions of the society, relationships and well-being. The survey on the US sample was on people's perceptions of their close interpersonal relationships and well-being. For the current analysis, we focused on participants' responses to questions on social class and life satisfaction, both of which were assessed towards the end of the surveys.

\section{Measures}

Subjective social class. Participants in both the Singapore and US samples rated their subjective social class using the MacArthur Scale of Subjective Status, which depicts a 10rung ladder, with people at the top having the best jobs, most education, and earning the most income (Adler et al., 2000). Participants were asked to rate where they judged themselves to be on the ladder in their own country. The mean rating for subjective social class was 5.7 (SD $=1.9)$ for the Singapore sample, and $5.0(S D=1.7)$ for the US sample.

Objective social class. In both samples, objective social class was assessed by educational attainment and income. For the Singapore sample, educational attainment was measured based on nine categories according to Singapore Standard Educational Classification 2015: (1) pre-primary, (2) primary, (3) secondary, (4) post-secondary (nontertiary), (5) polytechnic diploma, (6) professional qualification or other diploma, (7) Bachelor's or equivalent, (8) postgraduate diploma or certificate qualification, (9) Master's/PhD or other postgraduate degree. Monthly household income was assessed in Singapore dollars using 10 categories: (1) under $\$ 4000$, (2) $\$ 4,001-6,000$, (3) $\$ 6,001$ - 
$\$ 8,000,(4) \$ 8,001-\$ 10,000,(5) \$ 10,001-\$ 12,000,(6) \$ 12,001-\$ 14,000,(7) \$ 14,001$ $\$ 16,000,(8) \$ 16,001-\$ 18,000,(7) \$ 18,001-\$ 20,000,(8)$ over $\$ 20,000$. Educational attainment $(M=6.1, S D=1.7)$ and income $(M=4.0, S D=2.6)$ were standardised and averaged to form the composite variable of objective social class $(M=0.0, S D=0.8)$.

For the US sample, participants rated their educational attainment based on five categories: (1) less than high school, (2) high school graduation or equivalent, (3) some college, (4) college graduation, (5) professional / post-graduate degree. Annual household income was assessed in US dollars using eight categories: (1) under $\$ 15,000$, (2) $\$ 15,001$ $\$ 25,000,(3) \$ 25,001-\$ 35,000,(4) \$ 35,001-\$ 50,000,(5) \$ 50,001-\$ 75,000,(6) \$ 75,001-$ $\$ 100,000,(7) \$ 100,001-\$ 150,000,(8)$ over $\$ 150,000$. In this sample, household income was defined as the combined income of the people who had supported them growing up (e.g. parents, legal guardians). As with the Singapore sample, educational attainment $(M=3.5, S D$ $=0.8)$ and annual household income $(M=4.7, S D=1.8)$ were standardised and averaged to form the composite variable of objective social class $(M=0.0, S D=0.8)$.

Life satisfaction. Life satisfaction was assessed using the Satisfaction with Life scale (Diener et al., 1985) in both the Singapore sample $(\alpha=.91, M=4.3, S D=1.4)$ and the US sample $(\alpha=.91, M=4.5, S D=1.5)$. Participants responded to items such as "In most ways my life is close to my ideal." using 7-point scales $(1=$ strongly disagree; $7=$ strongly agree $)$.

\section{Results}

The associations amongst the various social class indicators are presented in Table 1 and Table 2 for Singapore and US samples respectively. Consistent with past research, subjective social class showed moderate correlations with various objective indicators of objective social class $(r \mathrm{~s}=.26$ to .41$)$ across both Singapore and US samples.

The primary prediction was that the relative benefit of perceiving higher subjective social class compared to low subjective social class for SWB will be stronger among high 
objective social class participants than low objective social class participants. To test this, we conducted a hierarchical linear regression within each of the samples. In the first model, we included both subjective social class and objective social class as predictors of life satisfaction to determine main effects. The interaction effect of subjective and objective social class was then included in the second model.

For the Singapore sample, subjective social class had a significant positive association with life satisfaction, $\beta=.52, t(1042)=18.75, p<.001$, while objective social class was not associated with life satisfaction, $\beta=.015, t(1042)=0.55, p=.580$. Importantly, the interaction between objective and subjective social class was significant, $\beta=.054, t(1041)=$ $2.02, p=.043$. Simple slopes analysis revealed patterns that were consistent with our hypothesis. Specifically, the relative benefit of subjective social class on life satisfaction was stronger when objective social class was high (at $1 \mathrm{SD}$ above the mean), $\beta=.59, t(1041)=$ $14.19, p<.001$, than when objective social class was low (at 1 SD below the mean), $\beta=.48$, $t(1041)=13.23, p<.001$. The pattern of this interaction effect is depicted in Figure 1.

For the US sample, subjective social class was significantly associated with higher life satisfaction, $\beta=.39, t(489)=8.54, p<.001$, while objective social class was not associated with life satisfaction, $\beta=.028, t(489)=0.62, p=.535$. Nonetheless, the interaction between objective and subjective social class was marginally significant, $\beta$ $=.082, t(488)=1.96, p=.051$. Simple slopes analyses revealed a similar pattern as in the Singapore sample: the relative benefit of subjective social class on life satisfaction was stronger when objective social class was high (at $1 \mathrm{SD}$ above the mean), $\beta=.47, t(488)=$ $7.54, p<.001$, than when objective social class was low (at 1 SD below the mean), $\beta=.31$, $t(488)=5.10, p<.001$. The pattern of this interaction effect is depicted in Figure 2.

We also repeated the analyses with gender included as covariate. The overall findings were largely similar, although the interaction term for the US sample achieved significance ( $p$ 
$=.034$ ) after controlling for gender. The complete findings for all regression analyses can be found in Table 3.

\section{Discussion}

In this first study, we found initial support for our primary hypothesis in two independent datasets. Specifically, we found that higher subjective social class was more strongly associated with higher life satisfaction when objective social class was high, but this association was significantly weaker when objective social class was low. This supported our hypothesis that there is a difference in the relative benefit of subjective social class when comparing across different objective social class levels. Although we theorized that this difference in relative benefit of subjective social class on life satisfaction is due to feelings of SBIU, we could not ascertain this in the current study since SBIU was not measured in these datasets. Therefore, to directly test the role of SBIU in explaining these patterns, we conducted Study 2 as a replication study that additionally included the measurement of SBIU.

\section{Study 2}

In this study, we sought to replicate the basic findings in Study 1, and also test if SBIU would explain the findings, by using another large online sample of Americans. Consistent with Study 1, we expected to see that the relative benefit of subjective social class on life satisfaction is stronger when objective social class is high, but weaker when objective social class is low. Furthermore, we tested our secondary hypothesis that the stronger association between subjective social class and life satisfaction would be mediated by lower perceived SBIU only when objective social class is high, but not when objective social class is low.

\section{Participants}

One thousand and thirty-eight participants (50\% females) from the US were recruited from Qualtrics panel, which aimed to provide nationally representative sample. As in Study 
1, eight participants with missing data on key variables were excluded from the analysis. The mean age for the sample was $45.3(S D=17.5)$. The median annual household income was $\$ 50,001-\$ 75,000$, and $50 \%$ had at least a college degree. In terms of ethnicity, $12 \%$ were African American, 6\% were Asian American, 75\% were European American, 2\% were Latin American, 5\% were Native American, and 1\% identified as "Other" ethnicities 5 .

\section{Procedure}

Similar to the Singapore sample in Study 1, this study was conducted as part of a larger survey on people's general perceptions of society, relationships and well-being. The survey included the same questions that were administered on the Singapore sample, with the addition of items measuring SBIU. Participants' responses to questions on social class, life satisfaction, and status identity uncertainty were examined in the current study. With the exception of age, participants' demographic information was measured at the end of the survey. The study was conducted in accordance with general ethical guidelines in psychology, approved by the Singapore Management University IRB.

\section{Measures}

Subjective social class. Participants rated their social class in US using a 10-rung ladder, with people at the top having the best jobs, most education, and earning the most income (Adler et al., 2000). The mean rating for subjective social class was $6.1(S D=2.3)$.

Objective social class. Objective social class was assessed by both educational attainment and income. Similar to the US sample in Study 1, participants rated their educational attainment based on five categories: (1) less than high school, (2) high school graduation or equivalent, (3) some college, (4) college graduation, (5) professional / postgraduate degree. Annual household income was assessed using nine categories in US dollars:

(1) less than $\$ 25,000,(2) \$ 25,001-\$ 50,000,(3) \$ 50,001-\$ 75,000,(4) \$ 75,001-\$ 100,000$, (5) $\$ 100,001-\$ 150,000,(6) \$ 150,001-\$ 200,000,(7) \$ 200,001-\$ 300,000,(8) 300,000-$ 
$\$ 500,000,(9)$ over $\$ 500,000$. Ratings for educational attainment $(M=4.1, S D=1.6)$ and income $(M=3.3, S D=2.1)$ were standardised and averaged to form the composite variable of objective social class $(M=0.0, S D=0.9)$.

Life satisfaction. Life satisfaction was assessed with the Satisfaction with Life scale (Diener et al., $1985 ; \alpha=.92, M=4.7, S D=1.5$ ).

Perceived SBIU. SBIU was measured by using 12-item scale developed by Destin et al. (2017). Sample items in this scale include "My beliefs about where I stand in society often conflict with one another", "Sometimes I feel that I am not really the social status that others think I am" and "My beliefs about where I stand in society seem to change frequently". Participants rated the items based on a 7 -point scale $(1=$ strongly disagree, $7=$ strongly agree; $\alpha=.90, M=4.3, S D=1.3)$. Higher scores reflect greater SBIU.

\section{Results}

As shown in Table 4, subjective social class showed moderate correlations ( $r \mathrm{~s}=.36$ to .47) with various objective indicators of objective social class. On the other hand, SBIU was only weakly correlated with social class indicators ( $r \mathrm{~s}=-.13$ to -.07$)$.

First, we sought to replicate the basic patterns observed in Study 1. As before, we conducted a hierarchical linear regression where in the first model, subjective social class and objective social class were included as predictors of life satisfaction, followed by their interaction included in the second model. In this analysis, we found that both subjective social class, $\beta=.36, t(1027)=11.57, p<.001$, and objective social class, $\beta=.19, t(1027)=$ $6.15, p<.001$, had significant positive associations with life satisfaction. Similar to Study 1 , the interaction between objective and subjective social class was significant, $\beta=.066$, $t(1026)=2.32, p=.021$. Simple slopes analysis showed that when objective social class was high, the relative benefit of subjective social class on life satisfaction was stronger at $\beta=.44$, $t(1026)=9.29, p<.001$ as compared to when objective social class was low (at 1 SD below 
the mean), $\beta=.31, t(1026)=8.28, p<.001$. This directly replicated the patterns observed in Study 1. This pattern of interaction is depicted in Figure 3. Including gender as covariate also did not significantly change the results. The results for the regression analyses can be found in Table 5.

Next, we examined whether these patterns would be explained by perceived SBIU to test our secondary hypothesis. The prediction was that the stronger relative benefit of higher subjective social class on life satisfaction would be mediated by lower perceived SBIU when objective social class is high, but not when objective social class is low. As past research has found that the effect of self-concept clarity on well-being was moderated by social class (Boucher, 2020; Na et al., 2018), we proposed that the association between SBIU and life satisfaction would similarly be moderated by objective social class. Hence, to examine our secondary hypothesis, we conducted a two-stage moderated mediation analysis using path analysis (Edwards \& Lambert, 2007). In this analysis, the moderating effect of objective social class was examined on the subjective social class and perceived SBIU association at the first stage, and the perceived SBIU and life satisfaction association at the second stage. Then, a bias-corrected bootstrap analysis tested if the indirect effect of subjective social class on life satisfaction via perceived SBIU was moderated by objective social class.

Objective social class significantly moderated the association between subjective social class and perceived SBIU at the first stage of the indirect effect, $\beta=-.15,95 \%$ CI $[-.20$, -.090], but did not significantly moderate the association between perceived SBIU and life satisfaction at the second stage, $\beta=-.041,95 \% \mathrm{CI}[-.10, .00]$. As can be observed from Figure 4, differences in the effects of low and high objective social class indicated that the association between subjective social class and SBIU in the first stage of the indirect effect was stronger for high objective social class than for low objective social class, $\beta=-.28$ $-.0060=-.29,95 \%$ CI $[-.40,-.18]$. On the other hand, the association between SBIU and life 
satisfaction in the second stage of the indirect effect was also stronger for high objective social class as compared to low objective social class, $\beta=-.052-.030=-.082,95 \% \mathrm{CI}$ $[-.20, .00]$, although this difference was non-significant (see Figure 5). Together, these differences in both the first and second stage resulted in a significantly bigger indirect effect for high objective social class as compared to low objective social class, $\beta=.015-.00018$ $=.015,95 \%$ CI $[.00077, .036]^{6}$. The mediation models for low and high objective social class are shown in Figure 6 and the standardised regression coefficients for the moderated mediation are presented in Table 6.

\section{Discussion}

Study 2 achieved two goals. First, we replicated the findings of Study 1 in this new US sample: higher subjective social class was again more strongly associated with higher life satisfaction when objective social class was high, but the association was significantly weaker when objective social class was low. This supports our primary hypothesis that the relative benefit of subjective social class on life satisfaction is stronger among high objective social class participants as compared to low objective social class participants.

Second, we directly tested the role of perceived status-based identity discrepancy in explaining the patterns through a two-stage moderated mediation model. Our findings showed that the difference in relative benefit of subjective social class on life satisfaction between high and low objective social class participants was mediated by SBIU, which supports our hypothesis. Specifically, for high objective social class participants, higher subjective social class was linked to lower SBIU, which subsequently predicted greater life satisfaction. Conversely, for low objective social class participants, subjective social class was not associated with SBIU, and SBIU was not significantly associated with life satisfaction. Extending the notion that self-concept clarity is more important amongst upperclass individuals (Boucher, 2020; Na et al., 2018), our findings further suggests that SBIU is 
also more salient and has deeper implications for well-being for high objective social class individuals than low objective social class individuals.

\section{General Discussion}

The current research investigated if the association between one's subjective social class and life satisfaction would differ depending on whether it is consistent with one's objective social class. Across three independent samples from Singapore and US, we found that the relative benefit of higher subjective social class on life satisfaction was stronger when objective social class was high, as compared to when objective social class was low. The pattern of interaction suggested that class-consistent perceptions of high social class were associated with higher life satisfaction as compared to class-inconsistent perceptions of social class.

We further postulated that the stronger relative benefit of subjective social class for high objective social class participants for life satisfaction is mediated through lower SBIU. SBIU was defined as a sense of incoherence and ambiguity in individuals' understanding of their social class and self-identity (Destin \& Debrosse, 2017; Destin et al., 2017), and has been associated with poorer psychological functioning and well-being (Destin et al., 2017). In the current paper, we suggested that SBIU would also be associated with the level of class consistency between one's subjective social class and objective social class. Therefore, in Study 2, we directly measured SBIU and examined if SBIU could explain the difference in the relative benefit of subjective social class on life satisfaction across high and low objective social class through a two-stage moderated mediation model. Consistent with our hypothesis, we found that for high objective social class individuals, higher subjective social class was associated with greater life satisfaction through lower SBIU. In contrast, for low objective social class individuals, the association between subjective social class and life satisfaction was not mediated by SBIU. 
There are a few possible reasons as to why individuals who are high in objective social class may perceive themselves to be of lower subjective social class and experience SBIU. One possibility is that some of the upper-class individuals, who were previously from disadvantaged backgrounds, may continue to perceive low status and experience SBIU due to difficulties with navigating changes in their status identities. For example, past research has shown that educational mobility among lower-class individuals often come at a cost, such as being at a higher risk of chronic stress and experiencing lower psychological well-being (E. Chen et al., 2015; Destin et al., 2017; Phillips et al., 2020). These effects have been linked to conflicting sociocultural contexts and norms experienced by lower-class students in middle class settings (E. Chen et al., 2015; Phillips et al., 2020; Stephens et al., 2012; Stephens et al., 2014), and lower sense of belongingness to their college identity (Destin et al., 2017), all of which may heighten SBIU. Our findings dovetail with this existing body of research, suggesting that upward social mobility confers less benefits for life satisfaction when individuals are not able to successfully integrate their experiences with what their objective social class should be.

Another reason may be the involuntary upward social comparison with high achieving peers in upper-class contexts. This is consistent with the big-fish-little-pond effect (BFLPE), where students in higher-ability academic settings tended to have poorer academic selfconcepts as compared to students in lower-ability academic settings, even after controlling for actual academic ability (Huguet et al., 2009; Marsh \& Parker, 1984; Marsh et al., 2008). When students were in a class where the average ability was higher, they perceived their relative standing in class to be lower as compared to students who were in a lower-ability class (Huguet et al., 2009). Similarly, we suggest that individuals who are objectively high in social class may also perceive themselves to be subjectively lower in social class as they engage in social comparison with others in their social circle, who are likely to be equally 
well-to-do. Social sampling processes may also be at play, such that upper-class individuals surrounded by similar others may overestimate the wealth of others (Dawtry et al., 2015), thereby downplaying their own social class. Although these comparison processes were not tested in the current studies, we suggest that future work should examine the role of these processes to enhance our understanding of the sources of status inconsistency and identity uncertainty, and how they may negatively affect SWB.

There are several limitations to the current research. Firstly, as we did not measure SBIU in the Singapore sample, we cannot ascertain if the same mechanism applies in a crosscultural sample. As Singapore has a predominantly interdependent culture, perceiving lower social class in comparison to objective social class in the Singapore context could also represent cultural values of humility and motivation to maintain harmony with others (Markus \& Kitayama, 1991) instead of SBIU. Consequently, for interdependent cultures, these cultural values could motivate individuals to both underestimate their subjective social class and report lower life satisfaction to avoid being seen as superior to others. Therefore, more research needs to be done to examine if the proposed mechanism of SBIU can be replicated in an interdependent culture.

Secondly, despite the large sample sizes in our studies, we noted that the effect sizes of the interaction between objective and subjective social class were small. The small effect size could be due to our broader samples of participants who may not be going though as many transitions in social class, and therefore experience greater class-consistency, compared to more specific samples like first generation college students, divorcees, and retirees. As well, our sample is considerably older as compared to the college samples used in past research (Destin et al., 2017). As people generally develop greater clarity and certainty in regard to their identities as they move from young adulthood to middle age (Diehl \& Hay, 2011; Lodi-Smith \& Roberts, 2010; Lodi-Smith et al., 2017), our sample may also experience 
lower levels of SBIU on average. Consequently, the observed effect sizes in our studies may be smaller because of lesser variation in the discrepancy between objective and subjective social class and lower levels of SBIU.

However, we also note that the current studies were conducted as part of a larger investigation on various aspects of social class and well-being. As such, we consider the current research to be an initial exploratory examination of the links between social class consistency, identity uncertainty, and SWB. It is also possible that the effects of social class inconsistency is mediated by other psychological processes, such as stronger identification with lower-status groups (Sharma \& Sharma, 2010). Specifically, when individuals identify more strongly with a lower status group (e.g. lower income group, or minority race) that is inconsistent with their objective social class, they might become vulnerable to the negative outcomes that are associated with lower-status group membership, despite the advantages conferred to them by their objective social class. We certainly encourage future research to use more targeted samples and assess for other plausible mechanisms to ascertain how inconsistency between subjective and objective social class may influence well-being and other outcomes more precisely.

Lastly, as the data in the current studies were all correlational in nature, we were unable to draw firm conclusions on whether social class inconsistency or SBIU indeed causes lower life satisfaction. In contrast to our hypothesis, the reverse causal pattern could be true: lower life satisfaction could influence one to be less certain about their status or rank in society. Future research can consider using experimental designs that manipulate feelings of SBIU or perceptions social class to provide stronger empirical evidence. For example, researchers could induce higher (or lower) perceptions of social class in experiments by instructing participants to imagine interacting with someone at the very bottom (or top) of society (Kraus et al., 2010; Kraus et al., 2013) or having them think about instances when 
they experienced inconsistencies in their social class identity, and subsequently assess the impact of these inductions on SWB.

In conclusion, the current research provides preliminary evidence on how the relative benefit of subjective social class on life satisfaction depends on its consistency with objective social class and the mediating role of SBIU on the association between social class and life satisfaction. These findings extend the current understanding on the different contexts and processes through which social class shapes SWB. We hope that this understanding will help to motivate future work on identifying potential psychological targets and ways to mitigate socioeconomic disparities in well-being. 


\section{References}

Adler, N. E., Epel, E. S., Castellazzo, G., \& Ickovics, J. R. (2000). Relationship of subjective and objective social status with psychological and physiological functioning: Preliminary data in healthy, White women. Health Psychology, 19(6), 586-592. https://doi.org/10.1037/0278-6133.19.6.586

Adler, N., \& Stewart, J. (2007). The MacArthur scale of subjective social status. San Francisco: MacArthur Research Network on SES \& Health.

Anderson, C., Kraus, M. W., Galinsky, A. D., \& Keltner, D. (2012). The local-ladder effect: Social status and subjective well-being. Psychological Science, 23(7), 764-771. https://doi.org/10.1177/0956797611434537

Baumgardner, A. H. (1990). To know oneself is to like oneself: Self-certainty and self-affect. Journal of Personality and Social Psychology, 58(6), 1062-1072. https://doi.org/10.1037/0022-3514.58.6.1062

Boucher, H. C. (2020). Social class and self-concept consistency: Implications for subjective well-being and felt authenticity. Self and Identity, $0(0), 1-17$. https://doi.org/10.1080/15298868.2020.1726443

Boyce, C. J., Brown, G. D. A., \& Moore, S. C. (2010). Money and happiness: Rank of income, not income, affects life satisfaction. Psychological Science, 21(4), 471-475. https://doi.org/10.1177/0956797610362671

Campbell, J. D. (1990). Self-esteem and clarity of the self-concept. Journal of Personality and Social Psychology, 59(3), 538-549. (1991-04413-001). https://doi.org/10.1037/0022-3514.59.3.538

Campbell, J. D., Trapnell, P. D., Heine, S. J., Katz, I. M., Lavallee, L. F., \& Lehman, D. R. (1996). Self-concept clarity: Measurement, personality correlates, and cultural 
boundaries. Journal of Personality and Social Psychology, 70(1), 141-156. (199601707-011). https://doi.org/10.1037/0022-3514.70.1.141

Chen, B., Luo, L., Wu, X., Chen, Y., \& Zhao, Y. (2020). Are the lower class really unhappy? Social class and subjective well-being in Chinese adolescents: Moderating role of sense of control and mediating role of self-esteem. Journal of Happiness Studies. https://doi.org/10.1007/s10902-020-00253-5

Chen, E., Miller, G. E., Brody, G. H., \& Lei, M. (2015). Neighborhood poverty, college attendance, and diverging profiles of substance use and allostatic load in rural African American youth. Clinical Psychological Science : A Journal of the Association for Psychological Science, 3(5), 675-685. https://doi.org/10.1177/2167702614546639

Cheung, F., \& Lucas, R. E. (2016). Income inequality is associated with stronger social comparison effects: The effect of relative income on life satisfaction. Journal of Personality and Social Psychology, 110(2), 332-341. https://doi.org/10.1037/pspp0000059

Cundiff, J. M., \& Matthews, K. A. (2017). Is subjective social status a unique correlate of physical health? A meta-analysis. Health Psychology, 36(12), 1109-1125. https://doi.org/10.1037/hea0000534

Dawtry, R. J., Sutton, R. M., \& Sibley, C. G. (2015). Why wealthier people think people are wealthier, and why it matters: From social sampling to attitudes to redistribution. Psychological Science, 26(9), 1389-1400. https://doi.org/10.1177/0956797615586560

Destin, M., \& Debrosse, R. (2017). Upward social mobility and identity. Current Opinion in Psychology, 18, 99-104. https://doi.org/10.1016/j.copsyc.2017.08.006

Destin, M., Rheinschmidt-Same, M., \& Richeson, J. A. (2017). Status-based identity: A conceptual approach integrating the social psychological study of socioeconomic 
status and identity. Perspectives on Psychological Science, 12(2), 270-289. https://doi.org/10.1177/1745691616664424

Diehl, M., \& Hay, E. L. (2011). Self-concept differentiation and self-concept clarity across adulthood: Associations with age and psychological well-being. The International Journal of Aging and Human Development, 73(2), 125-152. https://doi.org/10.2190/AG.73.2.b

Diener, E., Diener, M., \& Diener, C. (1995). Factors predicting the subjective well-being of nations. Journal of Personality and Social Psychology, 69(5), 851-864. https://doi.org/10.1037//0022-3514.69.5.851

Diener, E., Emmons, R. A., Larsen, R. J., \& Griffin, S. (1985). The satisfaction with life scale. Journal of Personality Assessment, 49(1), 71. https://doi.org/10.1207/s15327752jpa4901_13

Diener, E., Oishi, S., \& Lucas, R. E. (2003). Personality, culture, and subjective well-being: Emotional and cognitive evaluations of life. Annual Review of Psychology, 54(1), 403-425. https://doi.org/10.1146/annurev.psych.54.101601.145056

Edwards, J. R., \& Lambert, L. S. (2007). Methods for integrating moderation and mediation: A general analytical framework using moderated path analysis. Psychological Methods, 12(1), 1-22. https://doi.org/10.1037/1082-989X.12.1.1

Howell, R. T., \& Howell, C. J. (2008). The relation of economic status to subjective wellbeing in developing countries: A meta-analysis. Psychological Bulletin, 134(4), 536560. https://doi.org/10.1037/0033-2909.134.4.536

Huguet, P., Dumas, F., Marsh, H., Régner, I., Wheeler, L., Suls, J., ... Nezlek, J. (2009). Clarifying the role of social comparison in the big-fish-little-pond effect (BFLPE): An integrative study. Journal of Personality and Social Psychology, 97(1), 156-170. https://doi.org/10.1037/a0015558 
Kraus, M. W., Côté, S., \& Keltner, D. (2010). Social class, contextualism, and empathic accuracy. Psychological Science, 21(11), 1716-1723.

https://doi.org/10.1177/0956797610387613

Kraus, M. W., Piff, P. K., Mendoza-Denton, R., Rheinschmidt, M. L., \& Keltner, D. (2012). Social class, solipsism, and contextualism: How the rich are different from the poor. Psychological Review, 119(3), 546-572. https://doi.org/10.1037/a0028756

Kraus, M. W., Tan, J. J. X., \& Tannenbaum, M. B. (2013). The social ladder: A rank-based perspective on social class. Psychological Inquiry, 24(2), 81-96. https://doi.org/10.1080/1047840X.2013.778803

Lewandowski Jr., G. W., Nardone, N., \& Raines, A. J. (2010). The role of self-concept clarity in relationship quality. Self and Identity, 9(4), 416-433. https://doi.org/10.1080/15298860903332191

Lodi-Smith, J., \& Roberts, B. W. (2010). Getting to know me: Social role experiences and age differences in self-concept clarity during adulthood. Journal of Personality, 78(5), 1383-1410. https://doi.org/10.1111/j.1467-6494.2010.00655.x

Lodi-Smith, J., Spain, S. M., Cologgi, K., \& Roberts, B. W. (2017). Development of identity clarity and content in adulthood. Journal of Personality and Social Psychology, 112(5), 755-768. https://doi.org/10.1037/pspp0000091

Luttmer, E. F. P. (2005). Neighbors as negatives: Relative earnings and well-being. The Quarterly Journal of Economics, 120(3), 963-1002. https://doi.org/10.1093/qje/120.3.963

Markus, H., \& Kitayama, S. (1991). Culture and the self: Implications for cognition, emotion, and motivation. Psychological Review, 98(2), 224-253. https://doi.org/10.1037/0033295X.98.2.224 
Marsh, H. W., \& Parker, J. W. (1984). Determinants of student self-concept: Is it better to be a relatively large fish in a small pond even if you don't learn to swim as well? Journal of Personality and Social Psychology, 47(1), 213-231. (1984-32730-001). https://doi.org/10.1037/0022-3514.47.1.213

Marsh, H. W., Seaton, M., Trautwein, U., Lüdtke, O., Hau, K. T., O’Mara, A. J., \& Craven, R. G. (2008). The big-fish-little-pond-effect stands up to critical scrutiny: Implications for theory, methodology, and future research. Educational Psychology Review, 20(3), 319-350. https://doi.org/10.1007/s10648-008-9075-6

Na, J., Chan, M. Y., Lodi-Smith, J., \& Park, D. C. (2018). Social-class differences in selfconcept clarity and their implications for well-being. Journal of Health Psychology, 23(7), 951-960. https://doi.org/10.1177/1359105316643597

Nezlek, J. B., \& Plesko, R. M. (2001). Day-to-day relationships among self-concept clarity, self-esteem, daily events, and mood. Personality and Social Psychology Bulletin, 27(2), 201-211. https://doi.org/10.1177/0146167201272006

Oakes, J. M., \& Rossi, P. H. (2003). The measurement of SES in health research: Current practice and steps toward a new approach. Social Science \& Medicine, 56(4), 769784. https://doi.org/10.1016/S0277-9536(02)00073-4

Phillips, L. T., Stephens, N. M., Townsend, S. S. M., \& Goudeau, S. (2020). Access is not enough: Cultural mismatch persists to limit first-generation students' opportunities for achievement throughout college. Journal of Personality and Social Psychology, 119(5), 1112-1131. (2020-13880-001). https://doi.org/10.1037/pspi0000234

Ritchie, T. D., Sedikides, C., Wildschut, T., Arndt, J., \& Gidron, Y. (2011). Self-concept clarity mediates the relation between stress and subjective well-being. Self and Identity, 10(4), 493-508. https://doi.org/10.1080/15298868.2010.493066 
Sharma, S., \& Sharma, M. (2010). Self, social identity and psychological well-being. Psychological Studies, 55(2), 118-136. https://doi.org/10.1007/s12646-010-0011-8

Stansfeld, S. A., Head, J., \& Marmot, M. G. (1997). Explaining social class differences in depression and well-being. Social Psychiatry and Psychiatric Epidemiology, 33(1), 19. https://doi.org/10.1007/s001270050014

Stephens, N. M., Fryberg, S. A., Markus, H. R., Johnson, C. S., \& Covarrubias, R. (2012). Unseen disadvantage: How American universities' focus on independence undermines the academic performance of first-generation college students. Journal of Personality and Social Psychology, 102(6), 1178-1197. https://doi.org/10.1037/a0027143

Stephens, N. M., Markus, H. R., \& Phillips, L. T. (2014). Social class culture cycles: How three gateway contexts shape selves and fuel inequality. Annual Review of Psychology, 65(1), 611-634. https://doi.org/10.1146/annurev-psych-010213-115143

Stephens, N. M., Markus, H. R., \& Townsend, S. S. M. (2007). Choice as an act of meaning: The case of social class. Journal of Personality and Social Psychology, 93(5), 814 830. (2007-15390-008). https://doi.org/10.1037/0022-3514.93.5.814

Tan, J. J. X., Kraus, M. W., Carpenter, N. C., \& Adler, N. E. (2020). The association between objective and subjective socioeconomic status and subjective well-being: A metaanalytic review. Psychological Bulletin, 146(11), 970-1020. https://doi.org/10.1037/bul0000258

Tan, J. J. X., Kraus, M. W., Impett, E. A., \& Keltner, D. (2020). Partner commitment in close relationships mitigates social class differences in subjective well-being. Social Psychological and Personality Science, 11(1), 16-25.

https://doi.org/10.1177/1948550619837006 
Yu, S., \& Blader, S. L. (2020). Why does social class affect subjective well-being? The role of status and power. Personality and Social Psychology Bulletin, 46(3), 331-348. https://doi.org/10.1177/0146167219853841 
Data Availability Statement

All relevant data and materials of the current research are available on

https://tinyurl.com/classconsistency. 


\section{Endnotes}

${ }^{1}$ Given the well-established robust positive links that objective and subjective social class independently share with SWB (Tan, Kraus, Carpenter \& Adler, 2020), we expected that objective and subjective social class would have both independent and additive positive links to life satisfaction. This means that perceiving similarly high subjective social class as objective social class should be linked to the highest SWB, while perceiving similarly low subjective social class as objective social class should be linked to lower SWB, even though both cases are, by our conceptualization, high in class-consistency.

2 The percentages do not add up to 100 because of rounding.

${ }^{3}$ Two attention check items were embedded in the questionnaire. One asked participants to check "Not at all" on a 5-point scale $(1=$ Not at all, $5=$ Completely $)$, while the other question asked participants to check "Somewhat agree" on a 7-point scale $(1=$ Strongly disagree, $7=$ Strongly agree).

${ }^{4}$ The percentages do not add up to 100 because of rounding.

${ }^{5}$ The percentages do not add up to 100 because of rounding.

${ }^{6}$ Given that the second stage of the indirect effect was not significantly moderated by objective social class, we also tested another moderated mediation model with first stage moderation only. However, in this model, no significant difference was observed in the indirect effect between high and low objective social class, $\beta=.00,95 \%$ CI $[-.014, .015]$. This suggests that the first stage moderation alone was not sufficient to predict differences in the indirect effect. Therefore, although the second stage of the indirect effect was not significantly moderated by objective social class, we retained the two-stage moderated mediation model. The two-stage moderated mediation model is also more aligned with past research that suggested the moderating effect of social class on self-concept clarity (Boucher, 2020; Na et al., 2018). 


\section{Table 1}

Correlations between Objective and Subjective Social Class Indicators in Study 1 for Singapore Sample $(\mathrm{N}=1045)$.

\begin{tabular}{lcccc}
\hline Variable & $\begin{array}{c}\text { Household } \\
\text { income }\end{array}$ & Education & $\begin{array}{c}\text { Objective } \\
\text { social class }\end{array}$ & $\begin{array}{c}\text { Subjective } \\
\text { social class }\end{array}$ \\
\hline Household income & - & & & \\
Educational attainment & $.33 * * *$ & - & & \\
Objective social class & $.82 * * *$ & $.82 * * *$ & - & - \\
Subjective social class & $.29 * * *$ & $.26^{* * *}$ & $.34 * * *$ & $.53^{* * *}$ \\
\hline Life satisfaction & $.15^{* * *}$ & $.16^{* * *}$ & $.19^{* * *}$ & \\
\hline
\end{tabular}

Note. $* * *$ indicates $p<.001$. 


\section{Table 2}

Correlations between Objective and Subjective Social Class Indicators in Study 1 For US Sample $(\mathrm{N}=492)$.

\begin{tabular}{lcccc}
\hline \multicolumn{1}{c}{ Variable } & $\begin{array}{c}\text { Household } \\
\text { income }\end{array}$ & Education & $\begin{array}{c}\text { Objective } \\
\text { social class }\end{array}$ & $\begin{array}{c}\text { Subjective } \\
\text { social class }\end{array}$ \\
\hline Household income & - & & & \\
Educational attainment & $.23^{* * *}$ & - & & \\
Objective social class & $.78^{* * *}$ & $.78^{* * *}$ & - & - \\
Subjective social class & $.35^{* * *}$ & $.29^{* * *}$ & $.41^{* * *}$ & $.10^{* * * *}$ \\
Life satisfaction & $.13^{* *}$ & $.16^{* * *}$ & $.19^{* * *}$ & .4 \\
\hline
\end{tabular}

Note. $* *$ indicates $p<.01 . * * *$ indicates $p<.001$. 


\section{Table 3}

Results of Hierarchical Regression Analyses Performed in Study 1.

\begin{tabular}{|c|c|c|c|c|c|c|c|c|c|c|c|c|c|c|c|c|}
\hline & \multicolumn{8}{|c|}{$\underline{\text { Singapore sample }(\mathrm{N}=1045)}$} & \multicolumn{8}{|c|}{$\underline{\text { US sample }(\mathrm{N}=492)}$} \\
\hline & \multicolumn{4}{|c|}{$\underline{\text { Without covariate }}$} & \multicolumn{4}{|c|}{$\underline{\text { With covariate }}$} & \multicolumn{4}{|c|}{$\underline{\text { Without covariate }}$} & \multicolumn{4}{|c|}{$\underline{\text { With covariate }}$} \\
\hline & \multicolumn{2}{|c|}{ Step 1} & \multicolumn{2}{|c|}{ Step 2} & \multicolumn{2}{|c|}{ Step 1} & \multicolumn{2}{|c|}{ Step 2} & \multicolumn{2}{|c|}{ Step 1} & \multicolumn{2}{|c|}{ Step 2} & \multicolumn{2}{|c|}{ Step 1} & \multicolumn{2}{|c|}{ Step 2} \\
\hline & $\beta$ & $S E$ & $\beta$ & $S E$ & $\beta$ & $S E$ & $\beta$ & $S E$ & $\beta$ & $S E$ & $\beta$ & $S E$ & $\beta$ & $S E$ & $\beta$ & $S E$ \\
\hline Gender $(1=$ male, $0=$ female $)$ & & & & & .030 & .026 & .028 & .026 & & & & & $-.13 * *$ & .041 & $-.13^{* *}$ & .041 \\
\hline Subjective social class & $.52 * * *$ & .028 & $.53 * * *$ & .028 & $.52 * * *$ & .028 & $.53^{* * *}$ & .028 & $.39 * * *$ & .045 & $.39^{* * *}$ & .045 & $.40^{* * *}$ & .045 & $.40 * * *$ & .045 \\
\hline Objective social class & .015 & .028 & .0074 & .028 & .012 & .028 & .0043 & .028 & .028 & .045 & .040 & .046 & .022 & .045 & .034 & .045 \\
\hline $\begin{array}{l}\text { Subjective social class } \times \text { objective } \\
\text { social class }\end{array}$ & & & $.054 *$ & .027 & & & $.053^{*}$ & .027 & & & .082 & .042 & & & $.086^{*}$ & .042 \\
\hline$\Delta R^{2}$ & .28 & & .0028 & & .28 & & .0027 & & .16 & & .0066 & & .18 & & .0072 & \\
\hline
\end{tabular}

Note. Values in table are standardised regression coefficients.

$*$ indicates $p<.05$. ** indicates $p<.01 . * * *$ indicates $p<.001$. 


\section{Table 4}

Correlations between Key Variables in Study $2(\mathrm{~N}=1030)$.

\begin{tabular}{|c|c|c|c|c|c|}
\hline Variable & $\begin{array}{l}\text { Household } \\
\text { income }\end{array}$ & Education & $\begin{array}{l}\text { Objective social } \\
\text { class }\end{array}$ & $\begin{array}{l}\text { Subjective } \\
\text { social class }\end{array}$ & SBIU \\
\hline Household income & - & & & & \\
\hline Educational attainment & $.48 * * *$ & - & & & \\
\hline Objective social class & $.86^{* * *}$ & $.86^{* * *}$ & - & & \\
\hline Subjective social class & $.46 * * *$ & $.36 * * *$ & $.48 * * *$ & - & \\
\hline SBIU & $-.13 * * *$ & $-.066^{*}$ & $-.11 * * *$ & $-.13 * * *$ & - \\
\hline Life satisfaction & $.35^{* * *}$ & $.28 * * *$ & $.36^{* * *}$ & $.45^{* * *}$ & $-.086^{* *}$ \\
\hline
\end{tabular}

Note. $*$ indicates $p<.05 . * *$ indicates $p<.01 . * * *$ indicates $p<.001$. 


\section{Table 5}

Results of Hierarchical Regression Analyses Performed in Study 2.

\begin{tabular}{|c|c|c|c|c|c|c|c|c|}
\hline & & & & US san & $\mathrm{N}=103$ & & & \\
\hline & & With & covariate & & & $\underline{\mathrm{Wi}}$ & variate & \\
\hline & & p 1 & & & & & & \\
\hline & $\beta$ & $S E$ & $\beta$ & $S E$ & $\beta$ & $S E$ & $\beta$ & $S E$ \\
\hline Gender $(1=$ male, $0=$ female $)$ & & & & & .030 & .028 & .029 & .028 \\
\hline Subjective social class & $.36^{* * *}$ & .031 & $.38 * * *$ & .032 & $.36^{* * *}$ & .031 & $.38 * * *$ & .032 \\
\hline Objective social class & $.19 * * *$ & .031 & $.17 * * *$ & .032 & $.19 * * *$ & .032 & $.16^{* * *}$ & .033 \\
\hline $\begin{array}{l}\text { Subjective social class } \times \text { objective social } \\
\text { class }\end{array}$ & & & $.066^{*}$ & .029 & & & $.066^{*}$ & .029 \\
\hline$\Delta R^{2}$ & .24 & & .0040 & & .23 & & .0040 & \\
\hline
\end{tabular}

Note. $*$ indicates $p<.05 . * * *$ indicates $p<.001$ 


\section{Table 6}

Results of Moderated Mediation Performed in Study 2.

\begin{tabular}{|c|c|c|c|c|c|}
\hline \multirow{2}{*}{ Moderator variable } & \multicolumn{2}{|c|}{ Stage } & \multicolumn{3}{|c|}{ Effect } \\
\hline & First & Second & Direct & Indirect & Total \\
\hline \multicolumn{6}{|l|}{ Objective social class } \\
\hline Low & .0060 & .030 & $.36^{*}$ & .00021 & $.36^{*}$ \\
\hline High & $-.28 *$ & $-.052 *$ & $.36^{*}$ & $.015^{*}$ & $.37 *$ \\
\hline Differences & $-.29 *$ & $-.082 *$ & - & $.015^{*}$ & $.015^{*}$ \\
\hline
\end{tabular}

Note. The dependent variable for first-stage moderation is SBIU, while the dependent variable for second-stage moderation is life satisfaction.

The differences in simple effects were computed by subtracting the effects for low objective social class from the effects for high objective social class. As the direct effect is not moderated by objective social class, there is no difference between high and low objective social class.

Values in table represent standardised regression coefficients.

$*$ indicates $p<.05$. 


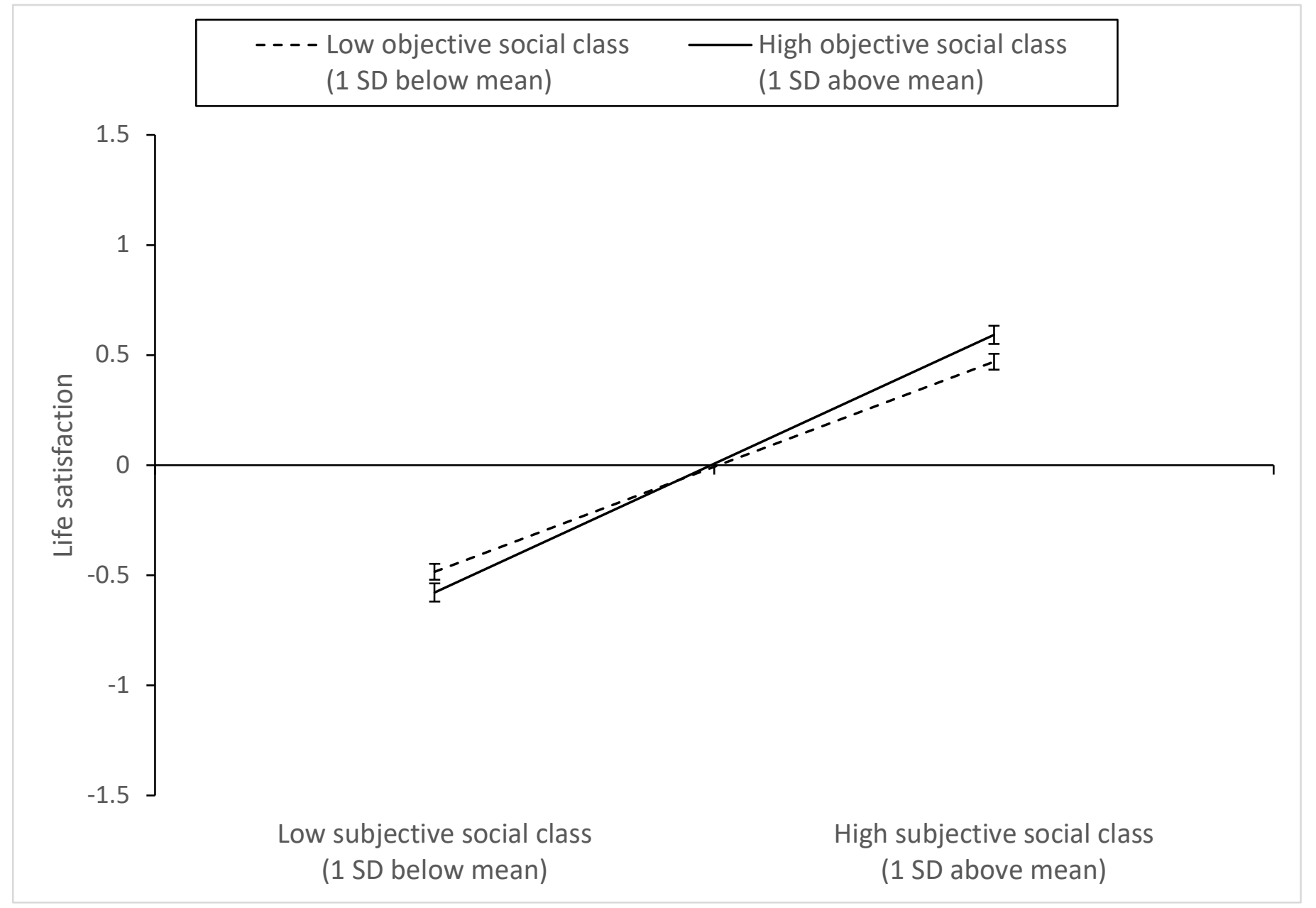

Figure 1. Life satisfaction as a function of subjective social class and objective social class for the Singapore sample in Study 1. Error bars represent the standard error of the estimate. 


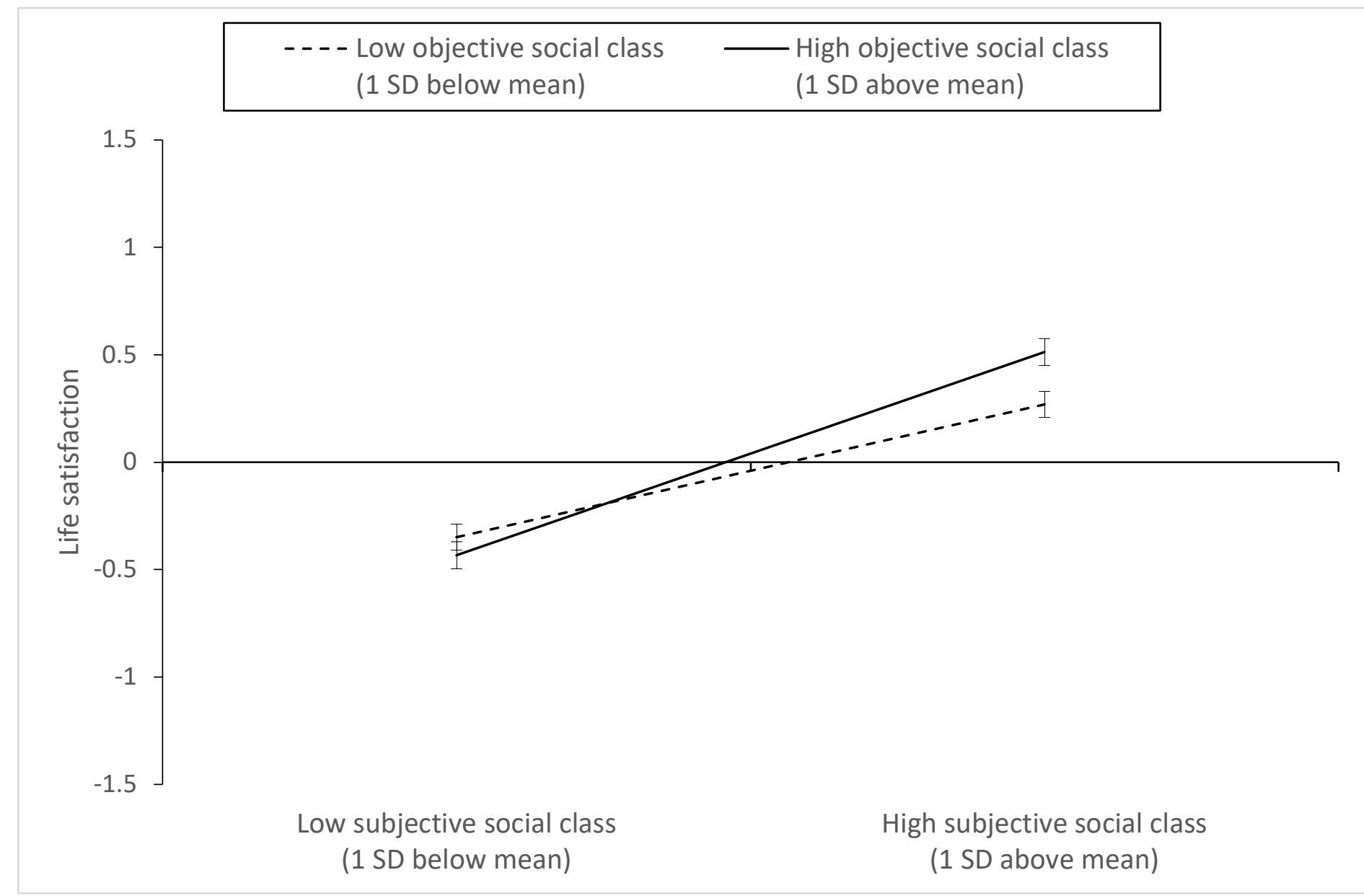

Figure 2. Life satisfaction as a function of subjective social class and objective social class for the US sample in Study 1. Error bars represent the standard error of the estimate. 


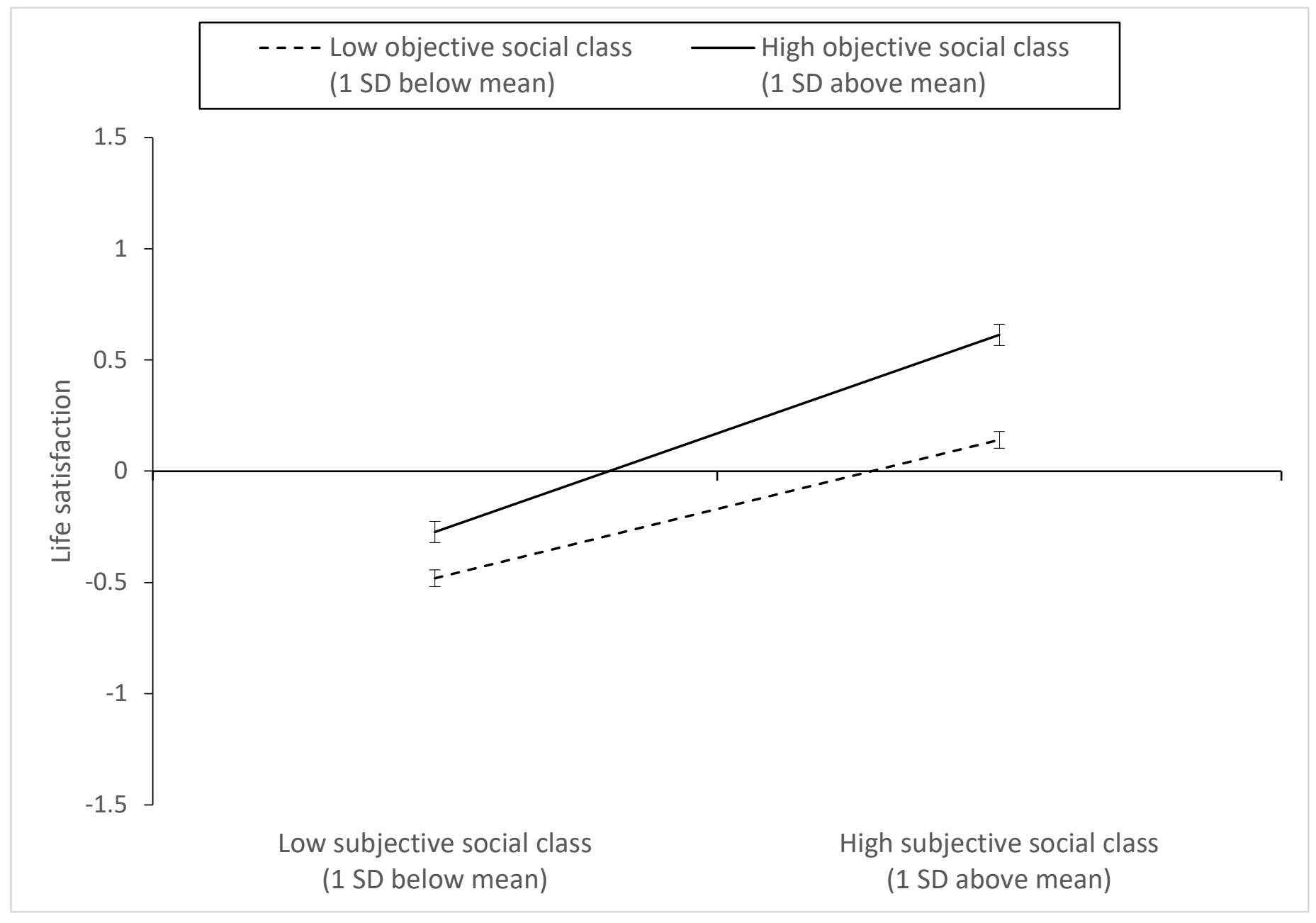

Figure 3. Life satisfaction as a function of subjective social class and objective social class in Study 2. Error bars represent the standard error of the estimate. 


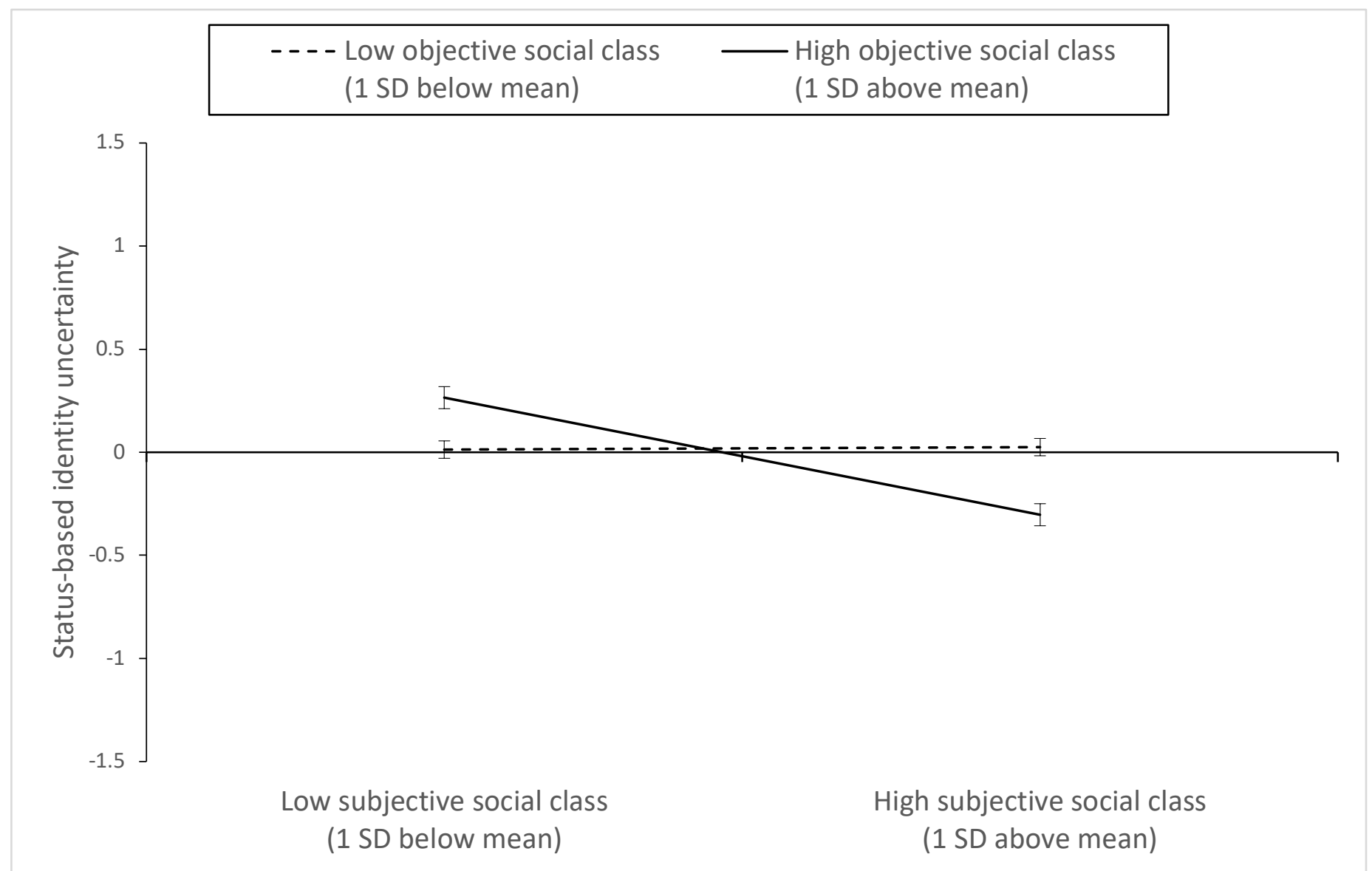

Figure 4. Effect of subjective social class and objective social class on perceived SBIU in the first stage of moderated mediation in Study 2.

Error bars represent the standard error of the estimate. 


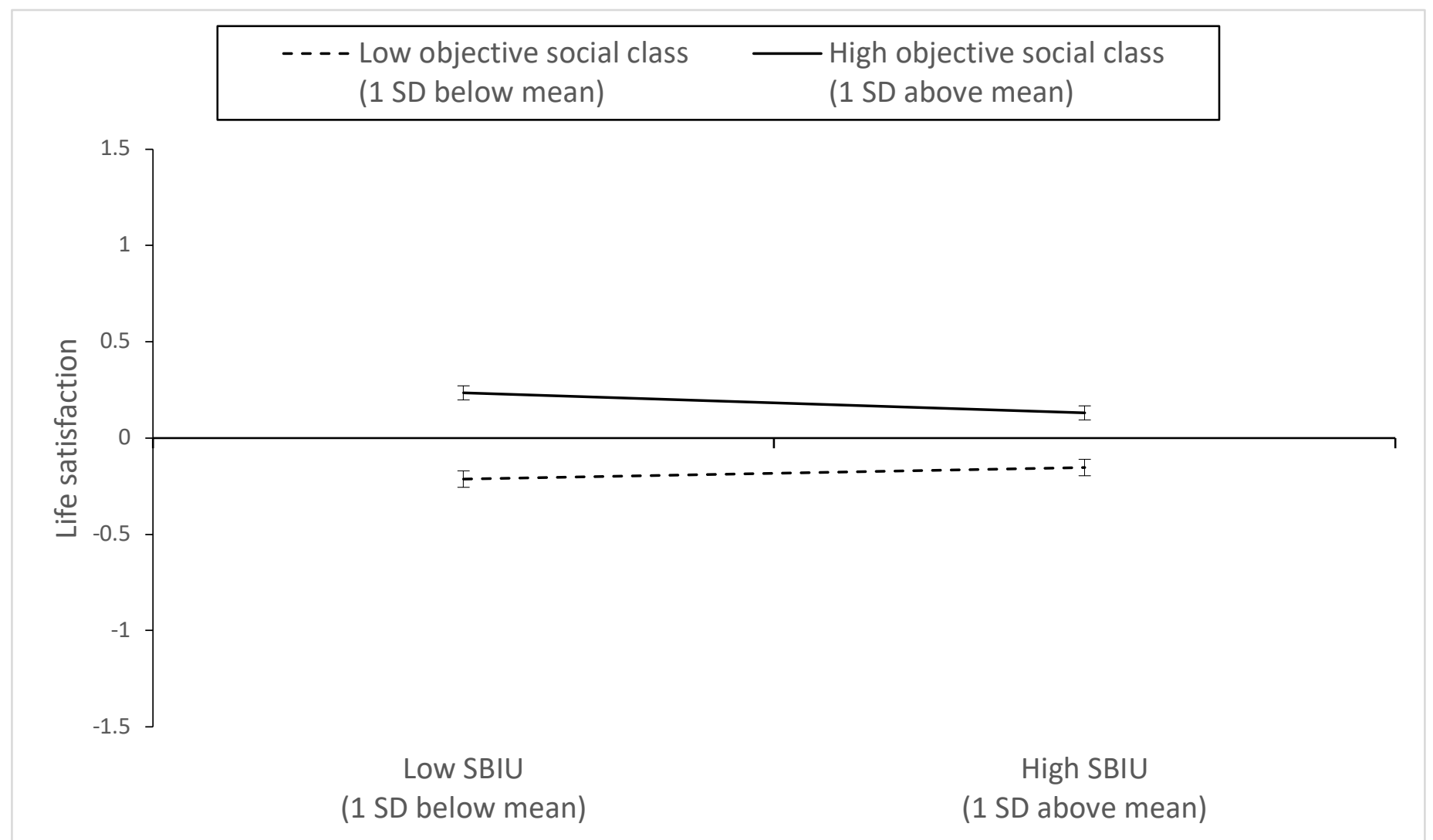

Figure 5. Effect of SBIU on life satisfaction moderated by objective social class in the second stage of moderated mediation in Study 2. Error bars represent the standard error of the estimate. 


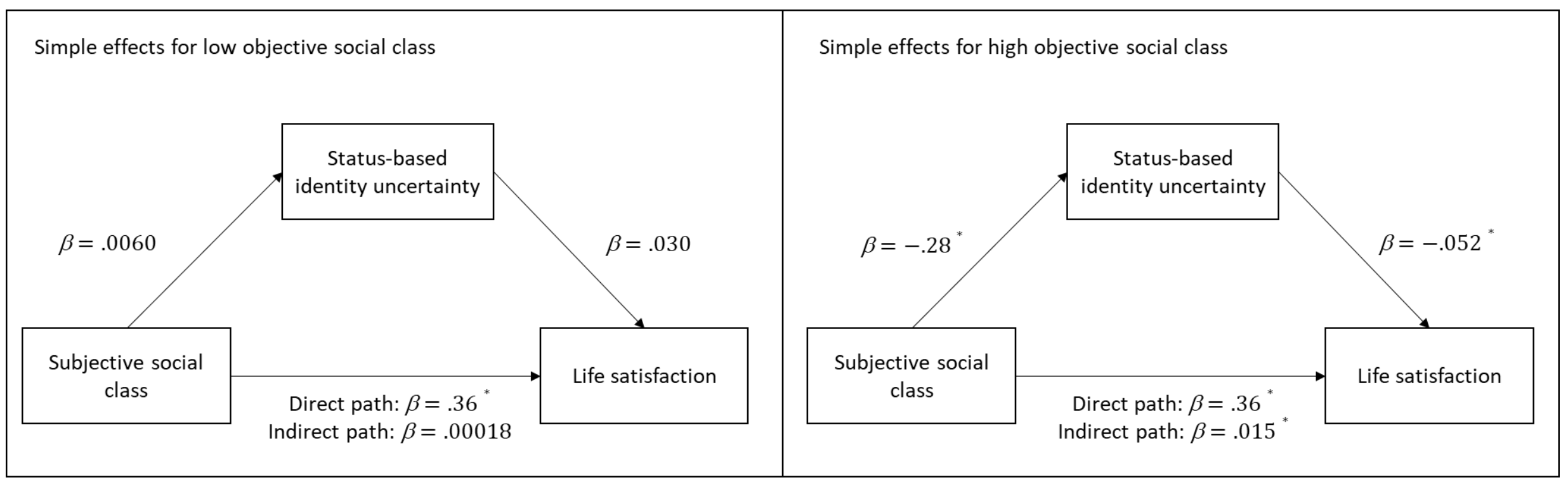

Figure 6. Moderated mediation model presented in Study 2 using objective social class as moderator. * indicates $p<.05$. 